This is the accepted manuscript of the article, which has been published in Sensors and Actuators B: Chemical. 2017, 243, 104-113. https://doi.org/10.1016/j.snb.2016.11.090

\title{
Stable immobilisation of His-tagged proteins on BLI biosensor surface using cobalt
}

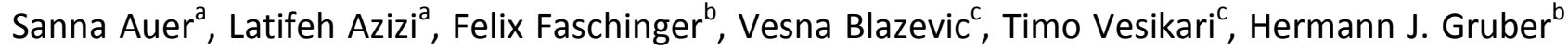
and Vesa P. Hytönen ${ }^{a^{*}}$

a BioMediTech, University of Tampere, Lääkärinkatu 1, FI-33520 Tampere, Finland, and Fimlab Laboratories, Biokatu 4, FI-33520 Tampere, Finland

${ }^{b}$ Institute of Biophysics, Johannes Kepler University, Gruberstrasse 40, 4020 Linz, Austria

${ }^{\mathrm{c}}$ School of Medicine, University of Tampere, Biokatu 8, FI-33520 Tampere, Finland

*Please address correspondence to Vesa P. Hytönen, BioMediTech, Biokatu 6, FI-33520 Tampere, Finland. Email: vesa.hytonen@uta.fi

\section{Abstract}

In biosensor experiments, ligand molecules need to be immobilized tightly on sensor surfaces for sensitive and robust detection of the analyte of interest. Stretches of histidines (His-tags) are typically inserted into recombinant proteins for affinity purification purposes, but can also be used in the immobilization of biosensors functionalized with Ni-NTA (nitrilotriacetic acid). The His-tag - Ni-NTA bond is, however, easily disrupted by factors including low pH, reducing agents, or chelating agents such as EDTA. In biosensing applications, a stable ligand immobilization that tolerates harsh conditions is preferable, because the sample matrix can vary from bodily fluids to waste waters. We describe here Co(III)-NTA bonding for tight immobilization of His-tagged proteins on Octet BLI-biosensors. The performance of the Ni(II)-NTA was compared to that of Co(III)-NTA using His-tagged avidins and norovirus proteins. Comparative studies were performed using biotin-iminodiacetic acid (IDA) for streptavidin sensor functionalization instead of the NTA surfaces provided by the manufacturer. It was noted that Co(III)-NTA offers highly stable immobilization of His-tagged protein, tolerating factors such as $0.7 \mathrm{M}$ imidazole, that is typically used for detaching proteins from Ni(II)-NTA -agarose used in protein purification columns. The good performance of Co(III)-NTA functionalized BLI sensor was demonstrated by detecting norovirus antibodies from human serum samples with sensors functionalized with Histagged virus-like particles. The use of Co-NTA sensors for attachment of His-tagged proteins is ideal in conditions, where the immobilized ligands need to be firmly attached and tolerate harsh chemical conditions. 
Keywords: His-tagged protein, Ni-NTA, biolayer interferometry, avidin-biotin, norovirus, nonlabelled detection

\section{Introduction}

Histidine tags, e.g. insertion of a stretch of 5-10 histidine amino acids in either the $\mathrm{N}$ - or Cterminus of a recombinant protein, are typically used as affinity tags for purification purposes [13]. Proteins with a histidine tag bind specifically to metal-functionalized affinity columns, from which they can be detached (for example by mild acid or imidazole treatment) and subsequently collected and separated from the source material. When the column is reloaded with metal (nickel, cobalt, zinc), it is readily available for reuse. Iminodiacetic acid (IDA) and nitrilotriacetic acid (NTA) are typically used as chelating agents for the immobilization of the metal.

But there are occasions when it would be ideal to use His-tags for more stable immobilization, such as the permanent functionalization of biosensors. In these applications, the reasonably easy detachment of His-tagged proteins from the metal-functionalized materials poses a problem. For example, the low concentrations of EDTA typically used as preservative in many commercial solutions are sufficient to detach the His-tagged protein from Ni-NTA. Originally, the idea of tight immobilization of His-tagged protein binding to agarose-NTA columns via cobalt(III) instead of nickel, was studied by Hale [4], where antibody affinity columns were constructed. Recently Wegner et al. [5-6] have continued the development of cobalt-based immobilization with NTAagarose and quartz crystal microbalance (QCM) sensors and proposed much more stable bonding of His-tagged proteins via Co(III)-NTA. Here the oxidation state of the cobalt is changed from state (II) to (III), which turns the complex into a slowly exchanging state, thus slowing down both the association and dissociation processes. In practice, this approach requires the formation of the complex in with cobalt in a reduced state $(\mathrm{Co}(\mathrm{II}))$, which is then converted to an oxidized state (Co(III)), using an oxidizer such as hydrogen peroxide.

Biolayer interferometry (BLI) is a label- and fluidics-free detection method that is also suitable for use with difficult sample matrices, such as serum. BLI is based on light intensity interference and enables real-time monitoring of ligand association or dissociation within the samples [7-10]. Interference changes between the intensities of the reflected light beams are used to measure changes in the molecular layer immobilised on the sensor surface. In the BLI measurement set-up the sensor tip is dipped into the sample matrix, even making difficult-to-process bodily fluids (such 
as saliva, urine, whole blood and stool) suitable sample materials. This approach makes it possible to operate with small sample volumes.

Avidins are tetrameric molecules capable of binding very tightly (with $\mathrm{fM}$ affinity) to four molecules of biotin (vitamin H) [11]. Originally avidins were extracted from chicken egg yolk and since, have been studied thoroughly and applied in several biotechnological applications [12-14]. One example of engineered avidin is so called chimeric avidin (ChiAvd) [15], which is stable at very high temperatures, as well as within high concentrations of organic solvents [16]. In addition to these superior stability characteristics, the surface properties of the molecule were also changed in order to make the $\mathrm{pl}$ of the molecule more neutral, which resulted in lower non-specific protein-protein interactions in neutral conditions [17], thus making it a very suitable molecule for biosensing applications. In the current study, this neutralized chimeric avidin (nChiAvd) was also Nterminally His-tagged. A schematic figure of the tetrameric avidin molecule used in this study exhibiting all characteristic mutations as well as the locations of the biotin binding sites is shown in the supplementary material, Fig. S1.

Noroviruses (NoV) infect people of all ages and are a major cause of acute epidemic gastroenteritis worldwide. It has been estimated that annually, there are over 20 million infections in the United States alone [18]. Symptoms of infection appear within $12-48$ hours and are characterised by acute onset of nausea, vomiting, abdominal cramps and diarrhoea. Small children, elderly people and immunocompromised persons can be severely infected by the virus and may require hospitalisation to prevent severe dehydration. Noroviruses are spread by contaminated food and water and from person to person via the faecal-oral pathway. They can be further transmitted to food and food contact surfaces by hands that are contaminated with the virus [19-20]. Virus-like particles (VLPs) have been used extensively to study NoV structure and stability, host-cell interactions, and as a tool in diagnostic serological assays [20-23]. Structural studies have shown that NoV capsid is composed almost entirely of the 58 kDa VP1 capsid protein [21], which selfassembles into empty capsids called virus-like particles (VLPs) when expressed recombinantly in insect cells [24], in yeast [25] or in plant cells [26]. There are 180 copies of VP1 in one NoV particle, and the diameter of the capsid is approximately $40 \mathrm{~nm}$ [27]. VP1 consists of two domains, the shell $(\mathrm{S})$ domain and the protruding $(\mathrm{P})$ domain, which are linked by a short hinge. $12 \mathrm{P}$-domain dimers form the NoV P-particle, the diameter of which is approximately 10-15 $\mathrm{nm}$ [28]. In this study we utilized recombinant NoV antigens, P-particles and norovirus-like particles (nVLPs). 
In our previous study, detection of norovirus antibodies from serum samples was conducted using BLI [29]. In order to increase the sensitivity of antibody detection, the BLI signal was enhanced through the addition of DAB (3,3'-diaminobenzidine), which precipitates on the sensor surface after horseradish peroxidase (HRP) oxidation [29-32]. However, the commercial DAB-reagents contain EDTA, which acts as a preservative stabilizing DAB. This makes the reliable use of a His-tag - metal immobilization strategy impossible, as the EDTA causes the dissociation of the His-tagged proteins from the sensor surfaces. For the above reason, alternative options for use of His-tag protein immobilization are needed.

In this study, we have studied cobalt-mediated immobilization of His-tagged proteins on BLIbiosensor surfaces. We utilized engineered avidin molecules and norovirus-like particles as ligands and demonstrated tight immobilization of these proteins onto sensors as well as the excellent detection of antibodies in human serum. NTA-Co(III) immobilization offers a stable and robust immobilization method and combined with BLI, it enables very fast and sensitive detection of analytes from both small sample volumes $(40 \mu \mathrm{l})$ and challenging sample matrices.

\section{Materials and methods}

A schematic presentation of the approach utilized in this study is shown in Fig. 1A. In the initial phase, Co-IDA surfaces were prepared; biotin-IDA molecules were immobilized on streptavidin (SA) sensors that made up a basement layer. Ni-NTA sensors provided by the manufacturer (Pall ForteBio, Menlo Park, CA, USA) were used as such as controls, but in contrast, the Co-NTA surfaces were made by stripping the metal ions from Ni-NTA sensors with EDTA, and then reloading the sensors with cobalt. In the second phase, avidin molecules were immobilized via their histidinetags to either the Co-IDA, Ni-NTA or to the Co-NTA sensors. It is noteworthy, as shown in the schematics, that there are fewer binding sites available in the IDA-functionalized sensors when compared to the NTA-functionalized sensors: in theory only one available binding site in each IDAfunctionalized sensor compared to three available binding sites in each NTA-functionalized sensor. This is because tris-NTA molecules [33] are used in the manufacturing of Ni-NTA sensors. The $3^{\text {rd }}$ phase consists of oxidation of the sensors, which converts the cobalt to the oxidized state (Co(III)). Then follows the challenging of the sensors by imidazole or low $\mathrm{pH}$ flush to evaluate the stability of the bonds between the protein and the sensor. In the last phase, the binding of the biotinylated- 
BSA is used to confirm the functionality of the sensor. Fig. 1B shows all these phases as representative BLI-sensorgrams.

[Figure 1 here]

Fig. 1. Experimental setup. (A) Schematic presentation of the different phases of the biosensing experiment studied with BLI (B) Typical BLI-sensorgrams showing the different phases described in the schematic presentation in (A). Solid lines correspond to experiments conducted under ideal conditions, while dashed lines represent experiments where the sensors were subjected to challenge with imidazole, which in the case of Ni-NTA, lead to an almost complete dissociation of the ligand from the sensor surface (phase 4).

Interferometry biosensing is based on the measurement of white light interference patterns reflected from a reference surface and a biofunctionalised sensor surface. A Fortebio Octet RED384 instrument equipped with 16 parallel biosensors (Pall ForteBio, Menlo Park, USA) was used in this study. All reagents were of analytical grade.

\subsection{Protein molecules}

\subsubsection{His-tagged nChiAvd}

His-tagged nChiAvd [17] was produced in BL21-Al cells using pYU25 plasmid (gift from Prof. Lloyd Ruddock, University of Oulu) as described by Hytönen et al. [34]. pYU25 encodes a polycistronic cassette containing $\mathrm{N}$-terminally His-tagged nChiAvd with the components for cytoplasmic disulfide bond formation (ERv1p and PDI). It is similar in structure to pKEHS1160 [35] which encodes BMP4 plus the components required for cytoplasmic disulfide bond formation, except that in pYU25, the ERv1p and PDI codons are optimized for E. coli expression and the T7 promoter has been replaced with a Ptac promoter. Codon optimization and gene synthesis were performed by GenScript. 


\subsubsection{Biotinylated-BSA}

Bovine serum albumin (BSA) molecules were biotinylated with EZ-Link Sulfo-NHS-SS-Biotin (Thermo Scientific, Waltham, MA, USA) as previously described [15].

\subsubsection{NoV P-particles and VLPS}

The production and purification of recombinant P-particles and His-tagged VLPS are described by Koho et al. [24] and Koho et al. [36] respectively. Briefly, a C-terminal polyhistidine tag was added to the GII-4 NoV capsid protein sequence by polymerase chain reaction using primers that contained the His-tag sequence. His-tagged NoV VLPs were expressed in insect cells and the Histagged norovirus P-particles in E. coli using the methodology described in [24] and both were purified by Ni-NTA metal ion affinity chromatography. Samples of His-tagged norovirus P-particle $\begin{array}{llll}\text { are } & \text { available } & \text { from } & \text { BioMediTech }\end{array}$ (http://www.biomeditech.fi/Protein_Shop/products.html).

\subsection{Serum samples}

Serum samples from NoV-infected subjects were collected as a part of a prospective etiological study at Tampere University Hospital in 2006-2008 [23-24] and stored at $-20^{\circ} \mathrm{C}$ until they were used. The study protocol was approved by the appropriate Ethics Committee, and informed patient consent was obtained.

\subsection{BLI-measurements}

The Ni-NTA or SA sensor surfaces (Pall ForteBio, Menlo Park, USA) were functionalized with either neutralized histidine-tagged chimeric avidin, NoV VLP or with P-particles at a concentration of 50 $\mu \mathrm{g} / \mathrm{ml}, 40 \mu \mathrm{g} / \mathrm{ml}$ or $60 \mu \mathrm{g} / \mathrm{ml}$, respectively, in PBS (10 mM NaPO $3,150 \mathrm{mM} \mathrm{NaCl}, \mathrm{pH}$ 7.4). PBS was used as a liquid phase in all of the BLI sensor functionalization steps. The sensors were soaked prior to run for 15-60 minutes in running buffer according to the manufacturer instructions. In these experiments only fresh, new sensors were used. The number of the sensors used was typically 2-6 per analyte and the data is presented as average \pm standard deviation of the measured responses. The stirring speed was set at $500 \mathrm{rpm}$, apart from with serum samples in the DAB-enhancement where $100 \mathrm{rpm}$ was used. The temperature was fixed at $25^{\circ} \mathrm{C}$. Black, tilted- 
bottom 384-well plates (Pall ForteBio, Menlo Park, USA) were used for sample measurement to ensure minimal drift in the measured signal between the analysis steps.

Typically, a BLI running set-up with Ni-NTA sensors and avidin-ligands was performed as follows: 1) the baseline of the sensors and device in buffer without any binding events was recorded first for 1 minute. 2) Sensors destined for coupling with cobalt, were soaked in 50 mM EDTA (ethylene diamine tetra-acetic acid) $\mathrm{pH} 8$ for $6 \mathrm{~min}$. The Ni-sensors run in parallel were soaked in PBS. 3) After each step the sensors were washed in PBS for 5 minutes. 4) Sensors were soaked in $\mathrm{CoCl}_{2}$ in double distilled deionized water (DDIW) at a concentration of $100 \mathrm{mg} / \mathrm{ml}$ for 6 minutes (the control Ni-sensors were soaked in plain PBS). 5) His-tagged nChiAvd (50 $\mu \mathrm{g} / \mathrm{ml}$ in PBS) was immobilised on the sensors for 6 minutes. 6) $0.3 \% \mathrm{H}_{2} \mathrm{O}_{2}$-oxidation (tested $\mathrm{H}_{2} \mathrm{O}_{2}$ concentration range was $0.03-0.3 \%$ ) took place for $10-15$ minutes (tested in a range of 5-60 $\mathrm{min}$ ) (the nonoxidized control Ni-sensors were soaked in plain PBS during the Co-sensor oxidation phase). 7) If the sensors were challenged with $0.7 \mathrm{M}$ imidazole, or $1 \mathrm{M}$ acetic acid $\mathrm{pH} 2$ for 6 minutes, it took place in this phase. 8) The binding of the second layer protein (biotinylated-BSA, $50 \mathrm{ug} / \mathrm{ml}$ in PBS) was measured for 6 minutes.

When running the serum samples with NoV VLP or P-particles (concentrations in the immobilisation phase were $40 \mu \mathrm{g} / \mathrm{ml}$ in PBS for NoV VLPs and $60 \mu \mathrm{g} / \mathrm{ml}$ in PBS for NoV P-particles), the steps after $\mathrm{H}_{2} \mathrm{O}_{2}$-oxidation and the possible challenge step were as follows: 9) Serum sample dilutions were applied for 6 minutes. 10) Anti-human IgG labelled with HRP (Vector laboratories Inc., USA, dilution 1:800 in buffer) was applied for 6 minutes. 11) Finally, DAB-enhancement phase was performed for 6 minutes. DAB was supplied by Thermo (Thermo Scientific, Rockford, IL, USA) and used as instructed by the supplier. HRP specifically bound to the sensor surfaces oxidises DAB, which subsequently precipitates on the sensor surface, causing an enhanced BLI signal.

In the case of SA-sensors functionalised with biotin-IDA, a typical run consisted of the following steps: 1) Measurement baseline was recorded for 1 minute. 2) $100 \mathrm{nM}$ Biotin-IDA was applied for 6 min. 3) After each binding phase the sensors were washed with PBS for 5 minutes. 4) His-tagged nChiAvd (50 $\mathrm{\mu g} / \mathrm{ml}$ in PBS) was immobilised on the sensors for 6 minutes. 5) Sensors were challenged with $0.7 \mathrm{M}$ imidazole, or $1 \mathrm{M}$ acetic acid $\mathrm{pH} 2$ for 6 minutes. 7) The binding of the second layer protein, biotinylated-BSA ( $50 \mu \mathrm{g} / \mathrm{ml}$ in PBS) was measured for 6 minutes. 


\subsection{Enzyme-linked immunosorbent assay (ELISA)}

The NoV antibodies from human serum samples were quantified by ELISA assays that were performed essentially as described before [24, 29, 38]. Briefly, NoV VLPs (50 ng/well) and Nov Pparticles (50 ng/well) were used as coating antigens in the ELISAs conducted with human sera. All reagents and test samples were diluted in $1 \%$ skimmed milk in phosphate-buffered saline (PBS)/0.05\% Tween 20, and the plates were washed with PBS/0.05\% Tween 20 between each incubation step. 96-well high binding microtitre plates were coated with the NoV particles (Costar, Corning, NY) overnight at $4^{\circ} \mathrm{C}$ and a concentration of $0.5 \mu \mathrm{g} / \mathrm{ml}$. Two-fold serial dilutions of serum samples were carried out to obtain a dilution range of 1:100-1:102,400 and were added to plates that had been blocked with $5 \%$ skimmed milk in PBS for $1 \mathrm{~h}$ at $22^{\circ} \mathrm{C}$. Antibodies that bound the NoV particles were then detected with goat anti-human IgG $(H+L)-H R P(1: 30,000)$ (Invitrogen, USA) for $1 \mathrm{~h}$ at $37^{\circ} \mathrm{C}$, followed by $0.4 \mathrm{mg} / \mathrm{mI}$ SIGMAFAST ${ }^{\text {TM }}$ OPD substrate (Sigma, Germany) for 15 minutes at $22^{\circ} \mathrm{C}$ with the final addition of $25 \mu \mathrm{l}$ of $2 \mathrm{M} \mathrm{H}_{2} \mathrm{SO}_{4}$ to stop the reaction. The optical density (OD) was measured at $490 \mathrm{~nm}$ on a Victor ${ }^{2} 1420$ Multilabel Counter (Wallac, Perkin Elmer) plate reader. Blank wells were incubated with buffer lacking VLPs and the data is expressed as the average OD of duplicate wells from a single experiment.

\subsection{Synthesis of Biotin-IDA}

\subsubsection{Synthesis of Biotin-PEG - -iminodiacetic acid, di-tert-butyl ester}

$20 \mathrm{mg}$ biotin- $\mathrm{PEG}_{3}$-amine ( $48 \mu \mathrm{mol}$, purchased from ThermoFisher Scientific), $32.9 \mathrm{mg}$ potassium carbonate $(238 \mu \mathrm{mol}, 5$ equiv.) and $7.9 \mathrm{mg}$ potassium iodide ( $48 \mu \mathrm{mol}, 1$ equiv.) were suspended in $219 \mu \mathrm{l}$ dimethylformamide in an argon atmosphere. $35.1 \mu$ tert-butyl bromoacetate (238 $\mu$ mol, 5 equiv.) was then added drop wise to the stirred suspension at room temperature and stirring was continued overnight. $1.1 \mathrm{ml}$ ethyl acetate was added to the mixture and the organic solution was washed three times with $0.2 \mathrm{ml}$ saturated sodium bicarbonate and three times with $0.2 \mathrm{ml}$ brine. The organic phase was separated, dried with anhydrous sodium sulphate and concentrated under reduced pressure. Then, the crude product was dissolved in dimethylsulfoxide and subsequently the solvent, together with high boiling impurities, was removed at 1-10 $\mathrm{Pa}$ to obtain $22.6 \mathrm{mg}$ biotin- $\mathrm{PEG}_{3}$-iminodiacetic acid, di-tert-butyl ester $(34.9 \mu \mathrm{mol}, 73 \%)$. The details of the ${ }^{1} \mathrm{H}$ NMR of the molecule as well as a schematic illustrating the synthesis (Fig. S2) can be found in the supplementary information. 


\subsubsection{Synthesis of Biotin-PEG $\quad$-iminodiacetic acid}

$22.6 \mathrm{mg}$ di-tert-butyl iminodiacetate-PEG 3 -biotin $(35 \mu \mathrm{mol})$ was dissolved in $350 \mu \mathrm{l}$ dry dichloromethane and $350 \mu$ trifluoroacetic acid was added. The mixture was stirred for $3 \mathrm{~h}$ under an argon atmosphere. The product formation was controlled by thin-layer chromatography $\left(R_{f}=\right.$ 0.36; chloroform/methanol/ammonia $=8 / 2 / 0.2$ ). After complete conversion of educt into product the solution was diluted with $7 \mathrm{ml}$ toluene, the solvents were removed under reduced pressure, chloroform was added and then removed at reduced pressure (2x) to obtain $18.5 \mathrm{mg}$ biotin-PEG ${ }_{3}^{-}$ iminodiacetic acid $(28.5 \mu \mathrm{mol}, 82 \%)$. The details of the ${ }^{1} \mathrm{H}-\mathrm{NMR}$ of the molecule can be found in the supplementary information.

\subsection{Homology modelling}

Structure determined for chimeric avidin [39] was used as a template to build a homology model of N-terminally His6-tagged charge-neutralized chimeric avidin mutant [17] using Modeller 9.16 [40]. The coordinates of NMR structure of chimeric avidin in biotin-bound form were obtained from protein data bank (PDB id 2MF6). Structural alignment of the individual subunits generated by Modeller were structurally superimposed using Bodil 0.81 [41]. The resulting tetrameric structure was then rendered using VMD 1.91 [42]. The coordinates of the bound biotins missing in the chimeric avidin structure (PDB id 2MF6) were obtained by superimposing the nChiAvd model with chicken avidin biotin complex X-ray structure (PDB id 2AVI; [43]). Adobe Photoshop CS6 was used to finalize the figure.

\section{Results and discussion}

\subsection{Effect of the sensor chemistry on ligand binding and analyte binding}

In order to achieve efficient cobalt-mediated immobilization of His-tagged proteins, we first optimized the immobilization chemistry and conditions. NTA and IDA are both widely used as carriers for metal immobilization. In a previous study, IDA-captured cobalt was used for antibody immobilization for preparation of affinity capture chromatography resin [4]. We therefore synthesized IDA-biotin and compared the performance of streptavidin sensors functionalized with IDA-biotin to commercially available NTA-functionalized sensors. These experiments were 
performed by using ambient conditions. Fig. 2A indicates the differences in the amount of protein bound to different BLI sensor surfaces: the Co-NTA surfaces bound the highest amount of protein leading to a total response of $\sim 12 \mathrm{~nm}$, while Ni-NTA surfaces resulted in an $\sim 8 \mathrm{~nm}$ response. Streptavidin sensors functionalized with Co-IDA resulted in only an $\sim 2 \mathrm{~nm}$ binding response. These results may be explained by the fact that NTA-sensors utilize tris-NTA [33] chemistry, and thus potentially offer higher numbers of binding sites for His-tagged proteins per sensor surface area when compared to IDA-functionalized streptavidin sensors. The thickness of the immobilized layer is above the diameter of avidin protein $(\sim 5 \mathrm{~nm})$, suggesting arrangement where more than one layer of proteins becomes bound to Co-NTA and Ni-NTA sensors. This may result from sensor surface having certain amount of roughness and thus multilayer protein arrangement. Unfortunately, the details of the biosensor surface architecture are not available.

[Figure 2 here]

Fig. 2. Optimization of the sensor functionalization. (A) The amount of the ligand, His-tagged avidin protein, bound to the Co-IDA, Ni-NTA or Co-NTA BLI sensor surfaces. (B) The amount of the second layer protein, biotinylated-BSA, bound to the BLI-sensors, comparing the sensor chemistry and whether or not the surfaces were imidazole challenged prior to the second layer protein binding. The results are an average of 3 individual sensors $\pm S D$.

Fig. 2B shows the amount of the second layer protein (biotinylated-BSA) bound to the sensors after challenging the surface with $0.7 \mathrm{M}$ imidazole. This condition is known to severely disturb weak metal-histidine interactions and is typically used, for example, in detaching proteins from $\mathrm{Ni}$ NTA columns when performing protein purification. We observed that oxidized Co-NTA and CoIDA sensors are capable of binding the same amounts of $2^{\text {nd }}$ layer protein regardless of whether either imidazole challenged or non-challenged surfaces were used. In contrast, imidazole-treated Ni-NTA sensors caused the detachment of the majority of the ligands ( $80 \%)$ from the surface, resulting in lower amounts of $2^{\text {nd }}$ layer protein binding.

3.2. Consequence of the oxidation time and $\mathrm{H}_{2} \mathrm{O}_{2}$ concentration on sensor stability 
One of the benefits of the use of biosensors is that they enable quicker assays as compared to methods such as ELISA. Therefore, we were interested to optimize the length of oxidation time needed for efficient immobilization of the His-tagged ligand. We thus studied the effect of oxidation time $(5-60 \mathrm{~min})$ and the $\mathrm{H}_{2} \mathrm{O}_{2}$ concentration $(0.03 \% ; 0.06 \% ; 0.3 \%)$ on sensor stability. Figure 3 indicates that sensors challenged with imidazole $(0.7 \mathrm{M})$ released over $70 \%$ of ligands from cobalt-functionalized sensors. In contrast, the oxidized cobalt sensors released only $30-40 \%$ of the ligands after such treatment. With the nickel sensors, more than $90 \%$ of the ligands detached. Low pH (1 M acetic acid $\mathrm{pH} 2$ ) was also tested in the challenge of the surfaces, and similar values were obtained. It was observed that with cobalt-sensors the longer oxidation times and higher $\mathrm{H}_{2} \mathrm{O}_{2}$ concentrations resulted in lower protein detachment after challenge.

We observed correlation between the amount of detached protein and the time period of oxidation; the longer the oxidation, the less ligand was detached (Fig. 3B). However, the differences between longer oxidation times were fairly small and consequently, an oxidation time of $10-15$ minutes, combined with $0.3 \% \mathrm{H}_{2} \mathrm{O}_{2}$ was used in the following experiments.

[Figure 3 here]

Fig. 3. Stability of the immobilized layer. (A) The amount of the ligand (His-tagged avidin) detached from the sensor surfaces when challenged with imidazole, depended on the hydrogen peroxide concentration induced sensor oxidation. Oxidation was performed for 10 and 30 minutes. (B) The amount of the ligand detached in imidazole challenge, depended on the sensor hydrogen peroxidase oxidation time $\left(0.3 \% \mathrm{H}_{2} \mathrm{O}_{2}\right)$. Control samples were treated for 10 minutes with PBS instead of oxidation with hydrogen peroxide. The results are an average of 3 individual sensors \pm $S D$.

\section{Spontaneous oxidation and influence of reduction on sensors}

The use of oxidizing agent may not be suitable for all the proteins because it potentially causes damage to protein structure. We noticed that the differences between the cobalt-functionalized sensors oxidized with $\mathrm{H}_{2} \mathrm{O}_{2}$ or washed simply "in buffer" were smaller than expected when compared to nickel-functionalized sensors challenged with imidazole (Fig. 3). In other words, we 
assumed that in a similar manner to the nickel sensors, almost all of the ligands should have detached from the cobalt-NTA sensors during the challenge. We thus hypothesized that cobaltfunctionalized sensors may become partially oxidized due to ambient conditions. In the following experiment, we tested this hypothesis through the inclusion of the reducing agent ( $\beta$ mercaptoethanol) in all solvents used in the experiment. We observed the following outcomes: 1 ) the amount of immobilized His-tagged protein was significantly lower in the presence of reducing agent when compared to conditions without reducing agent (Fig. 4). This may indicate that spontaneous oxidation of the cobalt takes place during the immobilization phase, thus increasing the amount of immobilized ligand due to irreversible binding to sensor. In the presence of reducing agent, the amount of immobilized His-tagged avidin is comparable to that observed for the Ni-NTA sensor (Fig. 2). 2) Another principal finding was that the sensor treated in the presence of reducing agent released, when challenged, clearly higher proportions of the immobilized ligand when compared to the sensor prepared in the buffers free of reducing agent (Fig. 3A). We assume that these observations are due to spontaneous oxidation taking place as a result of the presence of dissolved oxygen in the buffers. Spontaneous oxidation may be a preferred method for tight immobilization of delicate proteins, which might not withstand the harsher $\mathrm{H}_{2} \mathrm{O}_{2}$-treament.

[Figure 4 here]

Fig. 4. Effect of the oxidation treatment for the stability of the immobilized ligand layer. (A) Sensorgrams of $\mathrm{H}_{2} \mathrm{O}_{2}$-oxidized, spontaneously oxidized and B-mercaptoethanol reduced cobaltNTA sensors. The corresponding amounts of $(B)$ bound or detached proteins or $(C)$ the second protein layer (biotinylated-BSA) binding depending on the sensor chemistry. The results in panel $B$ and $C$ are an average of 2 individual sensors $\pm S D$.

The amounts of the avidin-ligand bound or detached in challenge and the amount of the $2^{\text {nd }}$ layer protein bound were compared in relation to oxidation or reduction as shown in Figs. 4B and 4C. $2^{\text {nd }}$ layer protein binding depended on the sensor chemistry and were $0.3 \mathrm{~nm}$ for $\beta$ mercaptoethanol-reduced, $1.2 \mathrm{~nm}$ for $\mathrm{H}_{2} \mathrm{O}_{2}$-oxidized or $1 \mathrm{~nm}$ for spontaneously oxidized sensors respectively. Overall, the oxidized cobalt sensor was the most resistant surface to $0.7 \mathrm{M}$ imidazole treatment (Fig. 4B). This resistance to imidazole treatment also correlated with the highest 
amount of bound biotinylated-BSA in the following phase (Fig. 4C). As expected, the reduced sample containing the $\beta$-mercaptoethanol also bound the lowest amount of biotinylated-BSA (Fig. $4 C)$.

With this in mind, we hypothesize that cobalt, when used for affinity chromatography, may also oxidize spontaneously and thus cause tight immobilization of the His-tagged protein to the column. Therefore, if the desire is to maximise the yield in chromatographic purification whilst utilising cobalt, it may be advisable to include small amounts of reducing agent in order to avoid irreversible binding of the target protein into the chromatographic column.

\subsection{Does the oxidation damage the immobilized proteins?}

The experiments described above suggest that cobalt is suitable for tight immobilization of Histagged proteins. However, it is also important to ensure that this methodology is suitable for applications where relevant ligands are immobilized for use in investigations with patient samples. In order to evaluate the effects of oxidation step for the immobilized protein layer, we conducted an experiment with two different norovirus-related proteins. P-particles are artificial assemblies of norovirus capsid proteins, while nVLPs represent the natural virus in terms of the morphology. Therefore, these particles are good examples of biological materials used in the biosensor analyses.

These antigens were immobilized to Co-NTA or Ni-NTA sensors. Selected Co-NTA sensors were then oxidized after the immobilization of the ligand using the protocol described above while reference sensors were soaked in PBS. Then, by using serum from patient with strong response to norovirus proteins $[24,29]$, the state of the immobilized antigen after oxidation was determined. The measured response after DAB enhancement is shown in Fig. 5. We found oxidation of the cobalt-immobilized sensor to show 3\% (P-particle) or 13\% (nVLP) higher response as compared to cobalt sensor treated in ambient conditions.

Importantly, the response measured with Co-NTA sensors were higher regardless of the oxidizing treatment as compared to Ni-NTA sensors: the measured increase in the binding response was smallest in the case of non-oxidized cobalt as compared to nickel for P-particle (1\%), while highest increase was observed for oxidized cobalt functionalized nVLP sensor, where more than $100 \%$ enhancement was seen as compared to nickel-functionalized reference. Therefore, based on this 
data, the oxidation does not cause severe damage to immobilized proteins, and is suitable for biologically relevant norovirus antigens.

[Figure 5 here]

Fig. 5. Comparison of $p H i$ is or $n V L P$ functionalized sensor responses with norovirus positive serum samples depending on the sensor chemistry: non-oxidized nickel, non-oxidized cobalt or oxidized cobalt. Results are an average of 2 independent sensors $\pm S D$.

\subsection{Feasibility of cobalt sensor use for the analysis of human serum samples}

One of the main problems encountered in our previous study [29] was the detachment of the ligands from the BLI-sensors due to the presence of interfering agents (such as EDTA) in some of the solutions used. Therefore, in the previous study, the His-tagged ligands were further immobilized via NHS-EDC to BLI Ni-NTA sensors in order to prevent their leakage during the analysis.

In order to evaluate the stability of the biofunctionalization layer, the sensors coated with norovirus P-particles were subjected to imidazole challenge prior to the introduction of the serum samples. Figure 6 shows that $\mathrm{Ni}$-sensors (oxidized with $0.3 \% \mathrm{H}_{2} \mathrm{O}_{2}$, as the Co-sensors), deliver no detectable signals for NoV antibody binding after imidazole treament. In comparison, robust signals were obtained with the oxidized cobalt-sensors.

Detachment of NoV P-particle ligands from the sensors was quite drastic, especially with the nickel sensors: over $95 \%$ of the ligands were detached with $0.7 \mathrm{M}$ imidazole, whilst there was $65 \%$ ligand detachment with the oxidized cobalt sensors (Fig. 6A, phase 4). In comparison, the avidin ligands showed less efficient detachment (over $70 \%$ with non-treated cobalt sensor and about $35 \%$ with oxidized cobalt; Fig. 3A). This may be a reflection of differences in the ligand-protein characteristics: avidin is a tetrameric protein with an extremely stable tetramer assembly. In contrast, the norovirus P-particle is a loose assembly of 24 subunits, which may partially dissociate when treated with $0.7 \mathrm{M}$ imidazole. However, importantly, the cobalt-based NoV-particlefunctionalized surface is capable of recognizing antibodies in human serum, while the nickelfunctionalized sensors completely lost their antibody-binding capacity in the imidazole treatment 
(Fig. 6B). A schematic illustration of NoV particle on BLI-sensor surface and the following BLI assay steps utilized in this study can be found from the supplementary information (Fig S3A.).

[Figure 6 here]

Fig. 6. Use of cobalt-functionalized sensors for quantification of serum antibodies. (A) BLIsensorgrams for NoV P-particle immobilization on cobalt- (blue) or nickel-functionalized (red) sensors. These sensors were used to detect antibodies from norovirus positive serum samples diluted 1:100 (phase 5). Phases 6 and 7 show HRP-labelled anti-human IgG binding and DAB enhancement, respectively. (B) Comparison of the BLI assay and ELISA for detection of NoV antibodies from human serum samples using NoV P-particle as an antigen. Grey lines represent the ELISA results, red lines the BLI results gained with oxidized cobalt sensors, and blue lines oxidized nickel sensors, both challenged with $0.7 \mathrm{M}$ imidazole prior to serum samples. Representative results based on 8 independent sensors are shown, the assay was repeated with similar results.

As noted in the previous study [29], serum alone induces a signal with BLI, but there are no differences between the response obtained from norovirus-positive donor serum and negative control serum samples prior to the DAB enhancement -phase. This suggests that the serum proteins do bind in an unspecific manner to the sensors, and therefore, the use of a secondary antibody against primary serum antibodies is needed to determine the amount of specifically bound primary antibodies.

Histidine tags can be straightforwardly added to the $\mathrm{N}$ - or $\mathrm{C}$ - terminus of proteins (or positioned in flexible regions within the protein) and have thus been widely employed for protein purification purposes. In this regard, the reversibility of the binding between the histidine-tag and nickel-NTA has been a positive trait, enabling the efficient release of bound proteins. However, biosensing applications and other protein immobilization protocols may require tighter conjugation methods. In addition, the presence of additives like EDTA and imidazole in protein solutions can also disturb histidine-nickel bonding. 
Fluidics-free BLI is a method that is very well suited for the screening of difficult and even "dirty" samples, such as serum, urine or stools or it can be used, for example, for different kinds of industrial process samples. For these types of sample, the immobilized ligands must also be robust; the ligand must remain immobilized throughout the whole analysis cycle. Previously, Hale [4] and Wegner et al. [5-6] also studied Co-NTA immobilization of His-tagged proteins. Their main findings were that there is tighter affinity in cobalt-bonding compared to nickel-bonding, and that oxidized Co-NTA is tolerant to EDTA and other reducing agents including cysteamine, DTT, TCEP and ascorbate. However, this is, to our knowledge, the first study where the high performance of a Co-NTA immobilization strategy combined with oxidation is demonstrated using serum samples and through the use of $\mathrm{BLI}$ sensor technology. The methodology presented is well suited for fast screening of samples. Ligand immobilization can be done in advance, and if, for example, only diagnostic samples are used, the last phases presented in this article could be run and results gained within 5-15 minutes. There is a clear need for these types of fast, yet very robust analytics where results are measurable straight from difficult sample matrices.

\section{Conclusions}

Oxidized cobalt sensors performed well in biosensor functionalization. 1) The amount of immobilised ligand is clearly higher when compared to Ni-NTA sensors. 2) The amount of ligand retained on the sensor after challenge is high (70-95\%). 3) The amount of the second layer protein bound remains reasonable. 4) We did not observe decrease in antigen-antibody binding due to oxidation. Spontaneous oxidation occurring due to the presence of dissolved oxygen may enable the utilization of this method for oxidation labile proteins. This means in practise, that this method is potentially exploitable without any special oxidation steps, unless, of course, the use of oxidation is desired for a faster process. This assay design is well suited for fast analysis of, for example, clinical samples, as demonstrated here. The different BLI assay phases can easily be quickened and/or shortened in order to reduce the current run time to 10-20 minutes, or even less, if ligand immobilization is performed beforehand.

\section{Acknowledgements}


We acknowledge Prof. Lloyd Ruddock for use of the pYU25 plasmid and Dr. Virginia Stone for text polishing. The Academy of Finland is also acknowledged for their financial support (projects 263540 and 290506). Biocenter Finland is acknowledged for the research infrastructure support.

\section{References}

[1] J. Schmitt, H. Hess, H.G. Stunnenberg, Affinity purification of histidine-tagged proteins, Mol. Biol. Rep. 18 (1993) 223-230. DOI 10.1007/BF01674434

[2] K. Terpe, Overview of tag protein fusions: from molecular and biochemical fundamentals to commercial systems, Appl. Microbial. Biotechnol. 60 (2003) 523-533. DOI 10.1007/s00253-0021158-6

[3] C.L. Young, Z.T. Britton, A.S. Robinson, Recombinant protein expression and purification: A comprehensive review of affinity tags and microbial applications, Biotechnol. J. 7 (2012) 620-634. DOI 10.1002/biot.201100155

[4] J.E. Hale, Irreversible, oriented immobilization of antibodies to cobalt-iminodiacetate resin for use as immunoaffinity media, Anal. Biochem. 231 (1995) 46-49. DOI:10.1006/abio.1995.1501

[5] S.V. Wegner, J.S. Spatz, Cobalt(III) as a stable and inert mediator ion between NTA and His6tagged proteins, Angew. Chem. Int. 52 (2013) 7593-7596. DOI: 10.1002/anie.201210317

[6] S.V. Wegner, F.C. Schenk, J. Spatz, Cobalt(III) mediated permanent and stable immobilization of histidine-tagged proteins on NTA-functionalized surfaces, Chem. Eur. J. 22 (2016) 3156-3162. DOI: 10.1002/chem.201504465

[7] A.M. Farkas, T.M. Kilgore, M.T. Lotze, Detecting DNA: getting and begetting cancer, Curr. Opin. Invest. Drugs 8 (2007) 981-986.

[8] R.L. Rich, D.G. Myszka, Higher-throughput, label-free, real-time molecular interaction analysis, Anal. Biochem. 361 (2007) 1-6. DOI: http://dx.doi.org/10.1016/j.ab.2006.10.040

[9] Y. Abdiche, D. Malashock, A. Pinkerton, J. Pons, Determining kinetics and affinities of protein interactions using a parallel real-time label-free biosensor, the Octet. Anal. Biochem. 377 (2008) 209-217. DOI: http://dx.doi.org/10.1016/j.ab.2008.03.035

[10] M.T. Lotze, Label-free, real-time detection system for molecular interaction analysis, US Patent 2009/0147264A1.

[11] N.M. Green, Avidin, Adv. Prot. Chem. 29 (1975) 85-133. DOI:10.1016/S0065-3233(08)604118.

[12] R.E. Eakin, W.A. McKinley, R.J. Williams, Egg-white injury in chicks and its relationship to a deficiency of Vitamin H (Biotin), Science 92 (1940) 224-4. DOI:10.1126/science.92.2384.224 
[13] N.M. Green, Avidin. 1. The use of (14-C)biotin for kinetic studies and for assay, Biochem. J. 89 (1963) 585-91.

[14] O.H. Laitinen, H.R. Nordlund, V.P. Hytönen, M.S. Kulomaa, Brave new (strept)avidins in biotechnology, Trends biotechnol. 25 (2007) 269-277. DOI:10.1016/j.tibtech.2007.04.001.

[15] V.P. Hytönen, J.A. Määttä, T.K. Nyholm, O. Livnah, Y. Eisenberg-Domovich, D. Hyre, H.R. Nordlund, J. Hörhä, E.A. Niskanen, T. Paldanius, T. Kulomaa, E.J. Porkka, P.S. Stayton, O.H. Laitinen, M.S. Kulomaa. Design and construction of highly stable, protease-resistant chimeric avidins, J. Biol. Chem. 280 (2005) 10228-10233. doi: 10.1074/jbc.M414196200

[16] J.A. Määttä, Y. Eisenberg-Domovich, H.R. Nordlund, R. Hayouka, M.S. Kulomaa, O. Livnah, V.P. Hytönen, Chimeric avidin shows stability against harsh chemical conditions - biochemical analysis and 3D structure, Biotechnol Bioeng 108 (2011) 481-490. doi: 10.1002/bit.22962

[17] S. Ray, R.T. Steven, F.M. Green, F. Höök, B. Taskinen, V.P. Hytönen, A.G. Shard, Neutralized chimeric avidin binding at a reference biosensor surface, Langmuir 31 (2015) 1921-1930. DOI: http://dx.doi.org/10.1021/la503213f

[18] E.F. Donaldson, L.C. Lindesmith, A.D. LoBue, R.S. Baric, Viral shape-shifting: Norovirus evasion of the human immune system, Nat. Rev. Microbiol. 8 (2010) 231-241. DOI: http://dx.doi.org/10.1038/nrmicro2296

[19] M. Koopmans, E. Duizer, Foodborne viruses: an emerging problem, Int. J. Food Microbiol. 90 (2004) 23-41. DOI: http://dx.doi.org/10.1016/S0168-1605(03)00169-7

[20] M.M. Patel, A.J. Hall, J. Vinje, U.D. Parashar, Noroviruses: a comprehensive review, J.Clin.Virol. 44 (2009) 1-8. DOI: http://dx.doi.org/10.1016/j.jcv.2008.10.009

[21] B.V. Prasad, M.E. Hardy, T. Dokland, J. Bella, M.G. Rossmann, M.K. Estes, X-ray crystallographic structure of the Norwalk virus capsid, Science. 286 (1999) 287-290. DOI: 10.1126/science.286.5438.287

[22] S.F. Ausar, T.R. Foubert, M.H. Hudson, T.S. Vedvick, C.R. Middaugh, Conformational stability and disassembly of Norwalk virus-like particles. Effect of $\mathrm{pH}$ and temperature, J.Biol.Chem. 281 (2006) 19478-19488. DOI: 10.1074/jbc.M603313200

[23] K. Nurminen, V. Blazevic, L. Huhti, S. Räsänen, T. Koho, V.P. Hytönen, T. Vesikari, Prevalence of norovirus Gll-4 antibodies in Finnish children, J. Med. Virol. 83 (2011) 525-531. DOI: $10.1002 / j m v .21990$

[24] T. Koho, L. Huhti, V. Blazevic, K. Nurminen, S.J. Butcher, P. Laurinmäki, N. Kalkkinen, G. Rönnholm, T. Vesikari, V.P. Hytönen, M.S. Kulomaa, Production and characterization of virus-like particles and the P domain protein of Gll.4 norovirus, J. Virol. Methods. 179 (2012) 1-7. DOI: http://dx.doi.org/10.1016/j.jviromet.2011.05.009 
[25] J. Tomé-Amat, L. Fleischer, S.A. Parker, C.L. Bardliving, C.A. Batt, Secreted production of assembled Norovirus virus-like particles from Pichia pastoris, Microb. Cell Fact. 13 (2014) 134. DOI: 10.1186/s12934-014-0134-z

[26] H.S. Mason, J.M. Ball, J.J. Shi, X. Jiang, M.K. Estes, C.J. Arntzen, Expression of Norwalk virus capsid protein in transgenic tobacco and potato and its oral immunogenicity in mice, Proc. Natl. Acad. Sci. USA 93 (1996) 5335-5340.

[27] X. Jiang, M. Wang, D.Y. Graham, M.K. Estes, Expression, self-assembly, and antigenicity of the Norwalk virus capsid protein J. Virol. 66 (1992) 6527-6532.

[28] M. Tan, X. Jian, A subviral nanoparticle for vaccine development against norovirus, rotavirus and influenza virus, Nanomedicine (Lond). 7 (2012) 889-897. DOI: http://dx.doi.org/10.2217\%2Fnnm.12.62

[29] S. Auer, T. Koho, H. Uusi-Kerttula, T. Vesikari, V. Blazevic, V.P. Hytönen, Rapid and sensitive detection of norovirus antibodies in human serum with a biolayer interferometry biosensor, Sens. Act. B. 221 (2015) 507-514. DOI: 10.1016/j.snb.2015.06.088

[30] V.D. Nadkarni, R.J. Linhardt, Enhancement of diaminobenzidine colorimetric signal in immunoblotting, BioTechniques 23 (1997) 382-385.

[31] S.H. Choo, W. Ma, J. Wei, Precipitating substrate for bio-layer interferometry, United States patent application publication. Pub. No.: US 2011/0236911 A1. Pub. Date: Sep. 29, 2011.

[32] Y. Liu, P. Estep, F. Reid, Y. Cao, T. Sun, Y. Yu, I. Caffry, Y. Xu, Picomolar solution phase affinity measurement by BLI-ELISA, Fortebio Interact. Winter 7 (2014) 7-9.

[33] S. Lata, A. Reichel, R. Brock, R. Tampé, J. Piehler, High-affinity adaptors for switchable recognition of histidine-tagged proteins J. Am. Chem. Soc. 127 (2005) 10205-15. DOI: 10.1021/ja050690c

[34] V.P. Hytönen, O.H. Laitinen, T.T. Airenne, H. Kidron, N.J. Meltola, E.J. Porkka, J. Hörhä, T. Paldanius, J.A. Määttä, H. Nordlund, M.S. Johnson, T.A. Salminen, K.J. Airenne, S. Ylä-Herttuala, M.S. Kulomaa, Efficient production of active chicken avidin using a bacterial signal peptide in Escherichia coli, Biochem. J. 384(Pt 2) (2004) 385-90. DOI: 10.1042/BJ20041114

[35] V.D. Nguyen, F. Hatahet, K.E.H. Salo, E. Enlund, C. Zhang, L.W. Ruddock, Pre-expression of a sulfhydryl oxidase significantly increases the yields of eukaryotic disulphide bond containing proteins expressed in the cytoplasm of E. coli, Microb. Cell. Fact. (2011) 10:1. DOI: 10.1186/14752859-10-1

[36] T. Koho, T.O. Ihalainen, M. Stark, H. Uusi-Kerttula, R. Wieneke, R. Rahikainen, V. Blazevic, V. Marjomäki, R. Tampe, M.S. Kulomaa, V.P. Hytönen, His-tagged norovirus-like particles: A versatile platform for cellular delivery and surface display, European Journal of Pharmaceutics and Biopharmaceutics 96 (2015) 22-31. DOI: http://dx.doi.org/10.1016/j.ejpb.2015.07.002 
[37] M. Malm, H. Uusi-Kerttula, T. Vesikari, V. Blazevic, High serum levels of norovirus genotypespecific blocking antibodies correlate with protection from infection in children, J. Infect. Dis. 210 (2014) 1755-1762. DOI: 10.1093/infdis/jiu361

[38] K. Tamminen, L. Huhti, T. Koho, S. Lappalainen, V.P. Hytönen, T. Vesikari, V. Blazevic, A comparison of immunogenicity of norovirus Gll-4 virus-like particles and P-particles, Immunology 135 (2012) 89-99. DOI: 10.1111/j.1365-2567.2011.03516.x.

[39] V.P. Hytönen, J.A.E. Määttä, T.K.M. Nyholm, O. Livnah, Y. Eisenberg-Domovich, D. Hyre, H.R. Nordlund, J. Hörhä, E.A. Niskanen, T. Paldanius, T. Kulomaa, E.J. Porkka, P.S. Stayton, O.H. Laitinen, M.S. Kulomaa, Design and construction of highly stable, protease-resistant chimeric avidins, J. Biol. Chem. 280 (2005) 10228-33. DOI: 10.1074/jbc.M414196200

[40] A. Sali, T.L. Blundell, Comparative protein modelling by satisfaction of spatial restrains, J. Mol. Biol 234 (1993) 779-815. DOI:10.1006/jmbi.1993.16266

[41] J.V. Lehtonen, D.J. Still, V.V. Rantanen, J. Ekholm, D. Björklund, Z. Iftikhar, M. Huhtala, S. Repo, A. Jussila, J. Jaakkola, O. Pentikäinen, T. Nyrönen, T. Salminen, M. Gyllenberg, M. Johnson, BODIL: a molecular modeling environment for structure-function analysis and drug design, J. Comput. Aided Mol. Des. 18 (2004) 401-419. DOI: 10.1007/s10822-004-3752-4

[42] W. Humphrey, A. Dalke, K. Schulten, VMD - Visual Molecular Dynamics, J. Molec. Graphics, 14 (1996) 33-38.

[43] O. Livnah, E.A. Bayer, M. Wilchek, J.L. Sussman, Three-dimensional structures of avidin and the avidin-biotin complex, Proc. Natl. Acad. Sci. USA 90 (1993) 5076-80. 


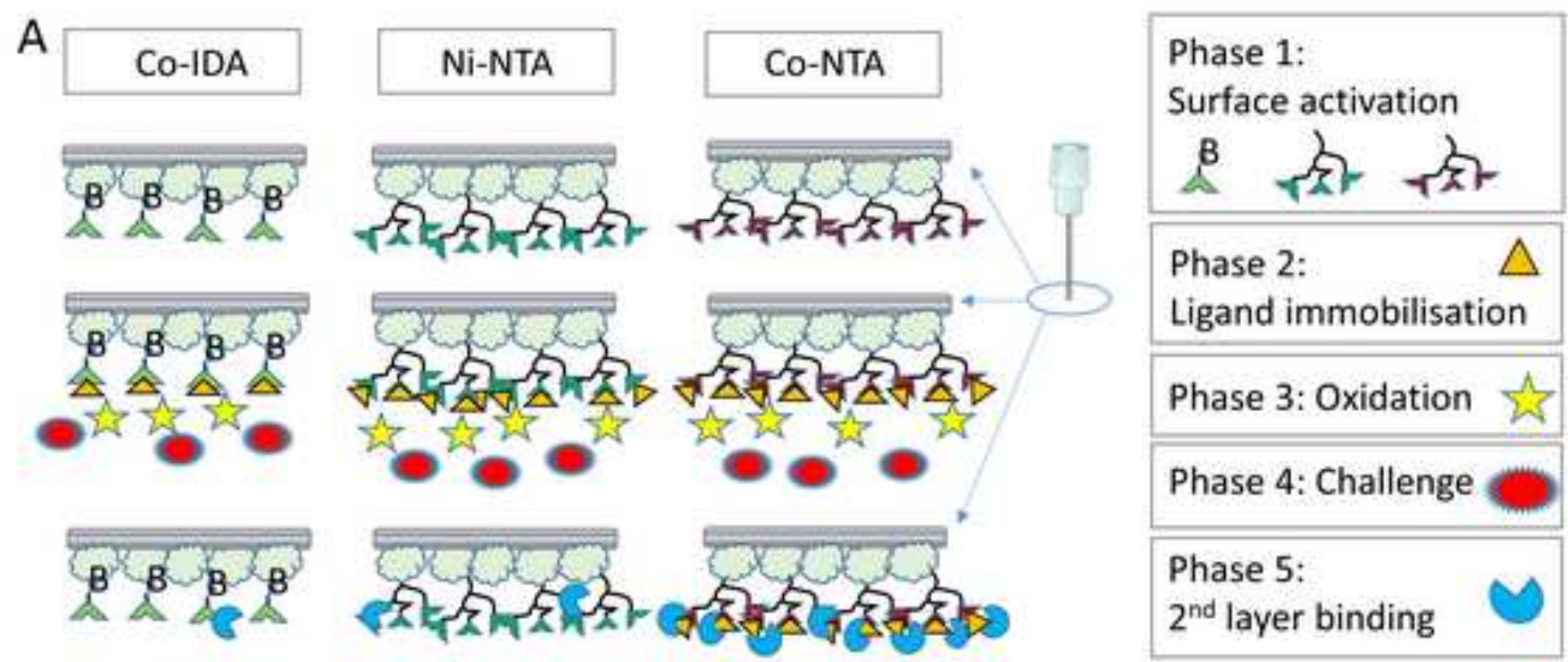

B

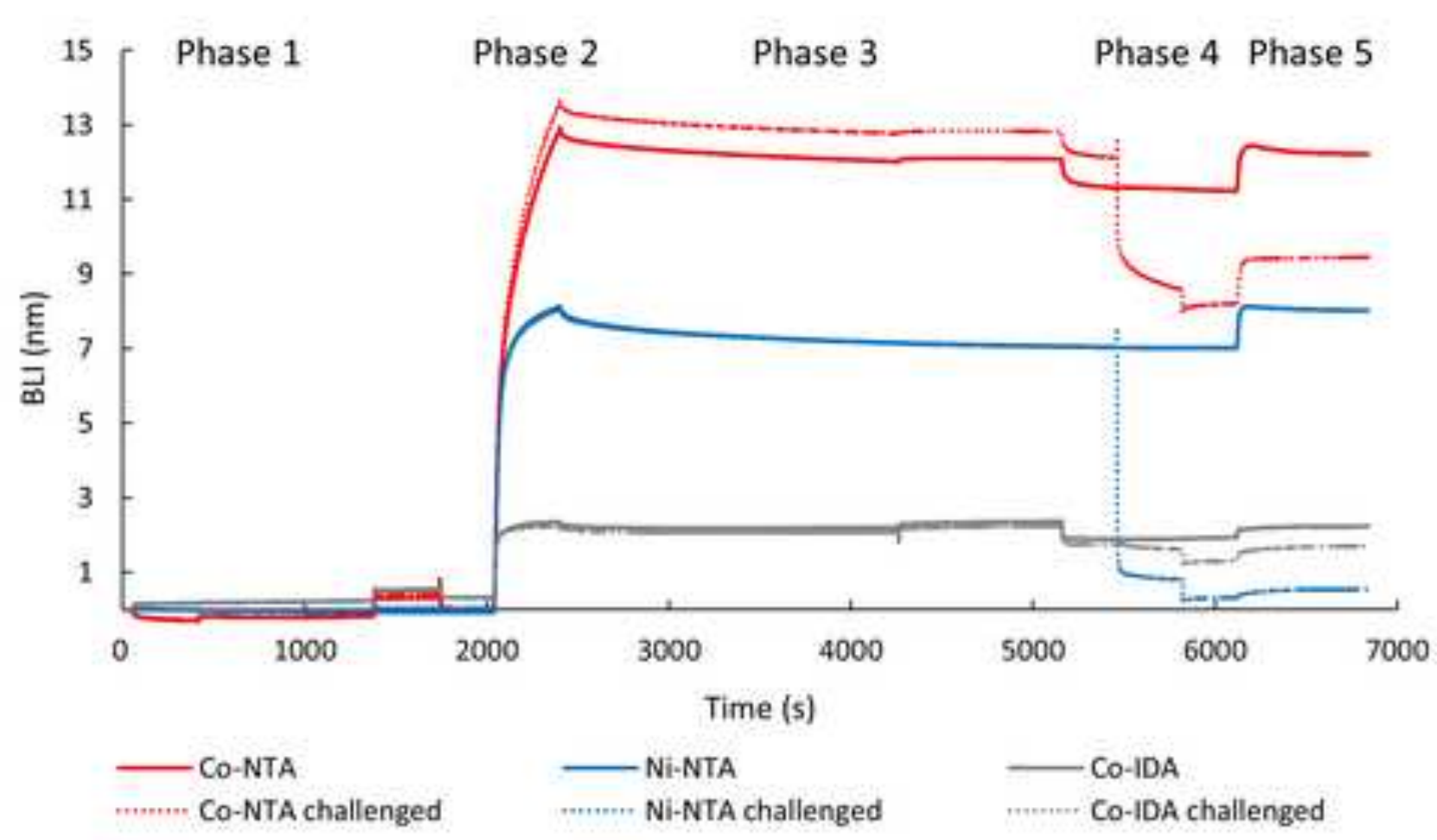


Click here to download high resolution image

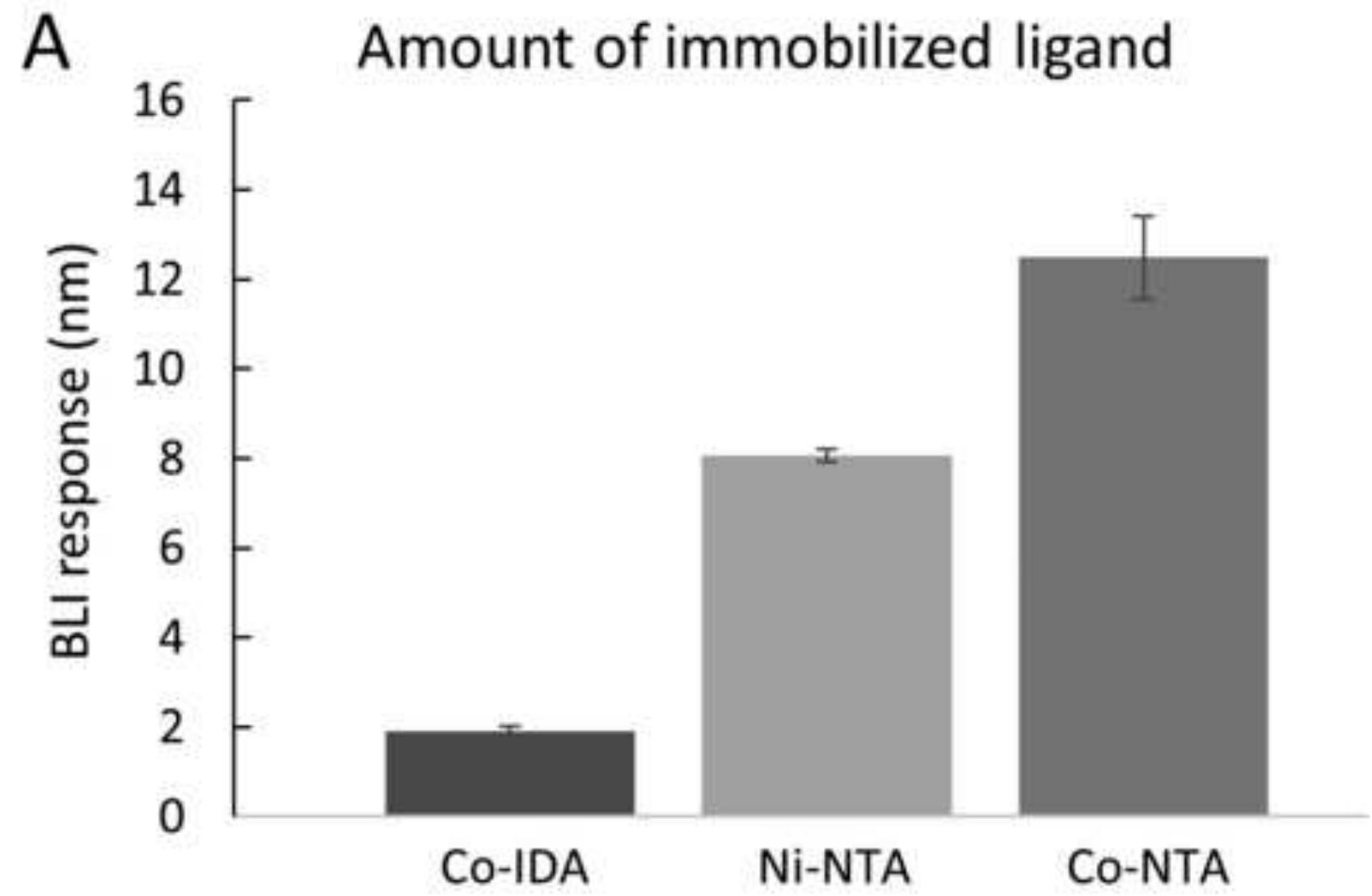

B

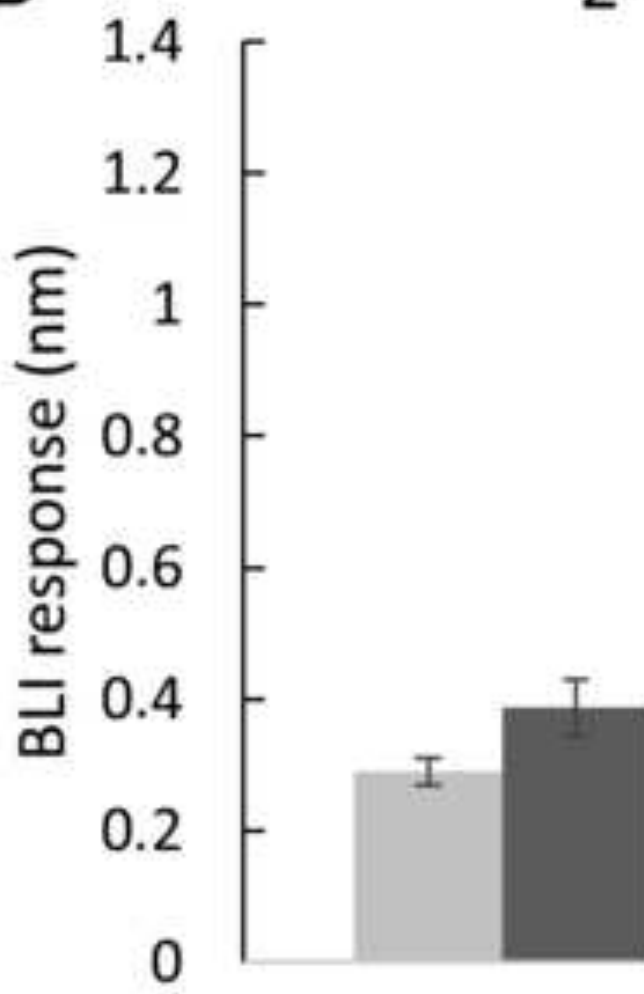

$2^{\text {nd }}$ layer protein binding

Co-IDA

Ni-NTA

Co-NTA

Non-challenged $\quad$ Challenged 

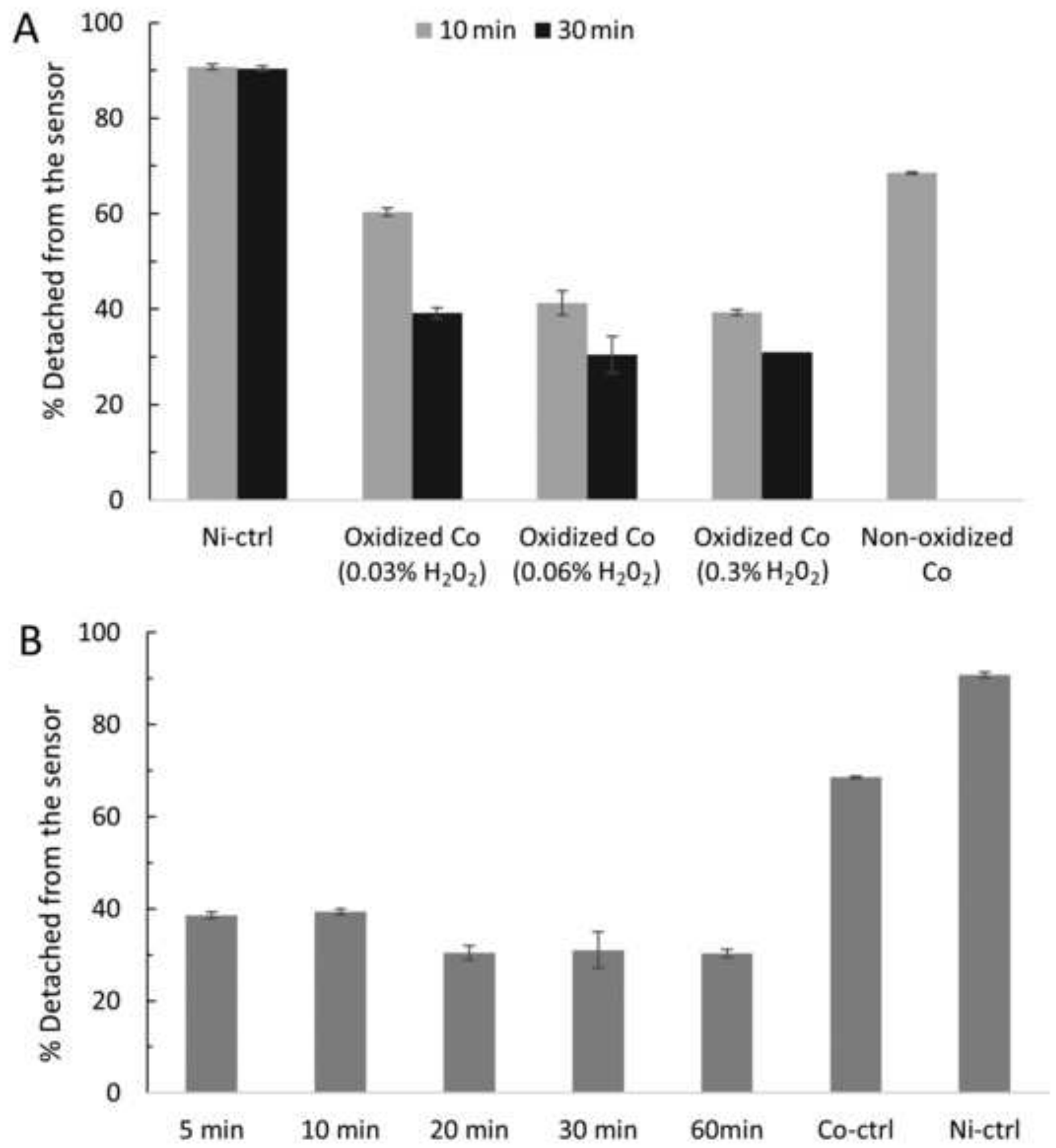
Click here to download high resolution image
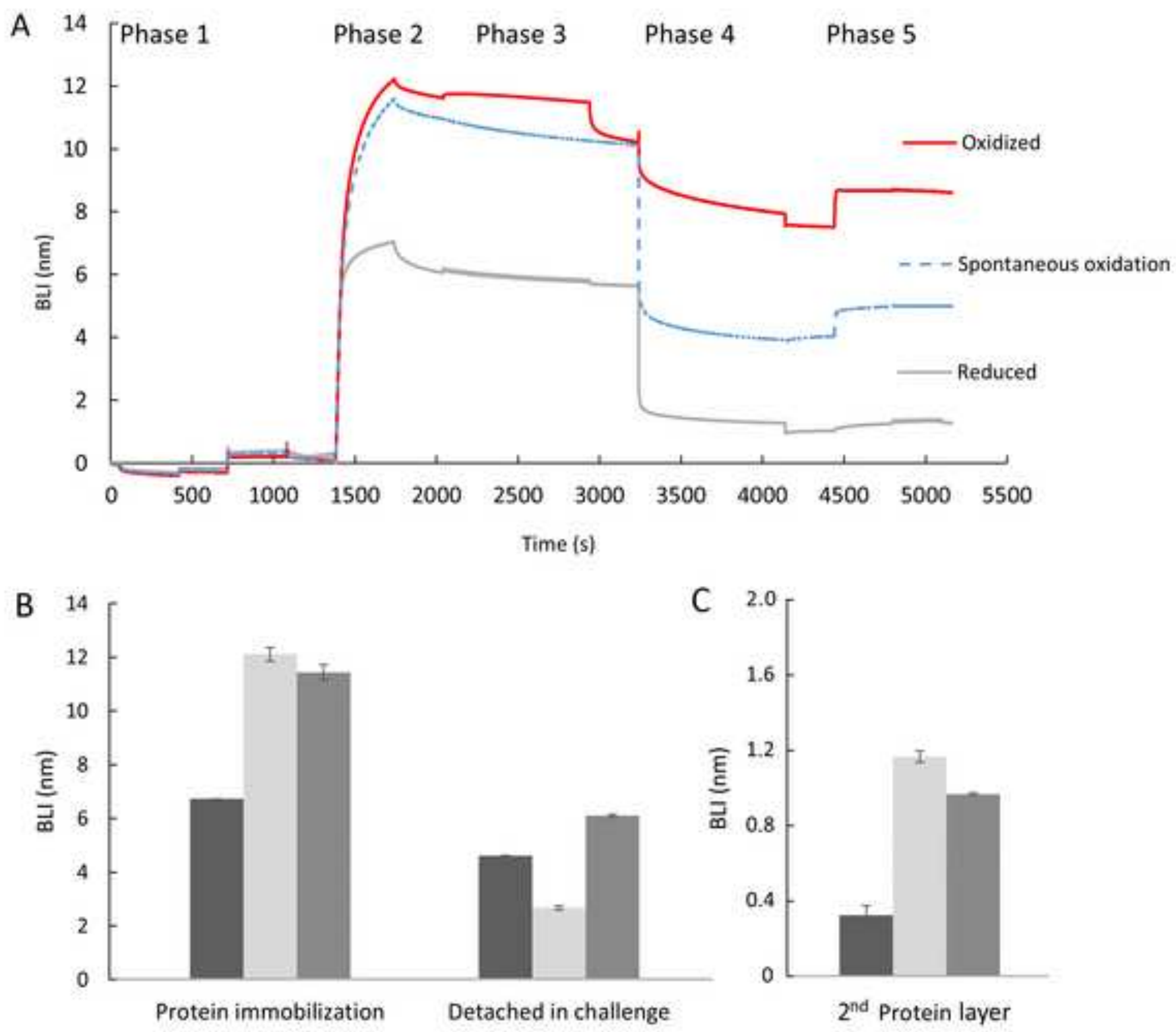

neduced

Oxidized

Epontaneous oxidation 


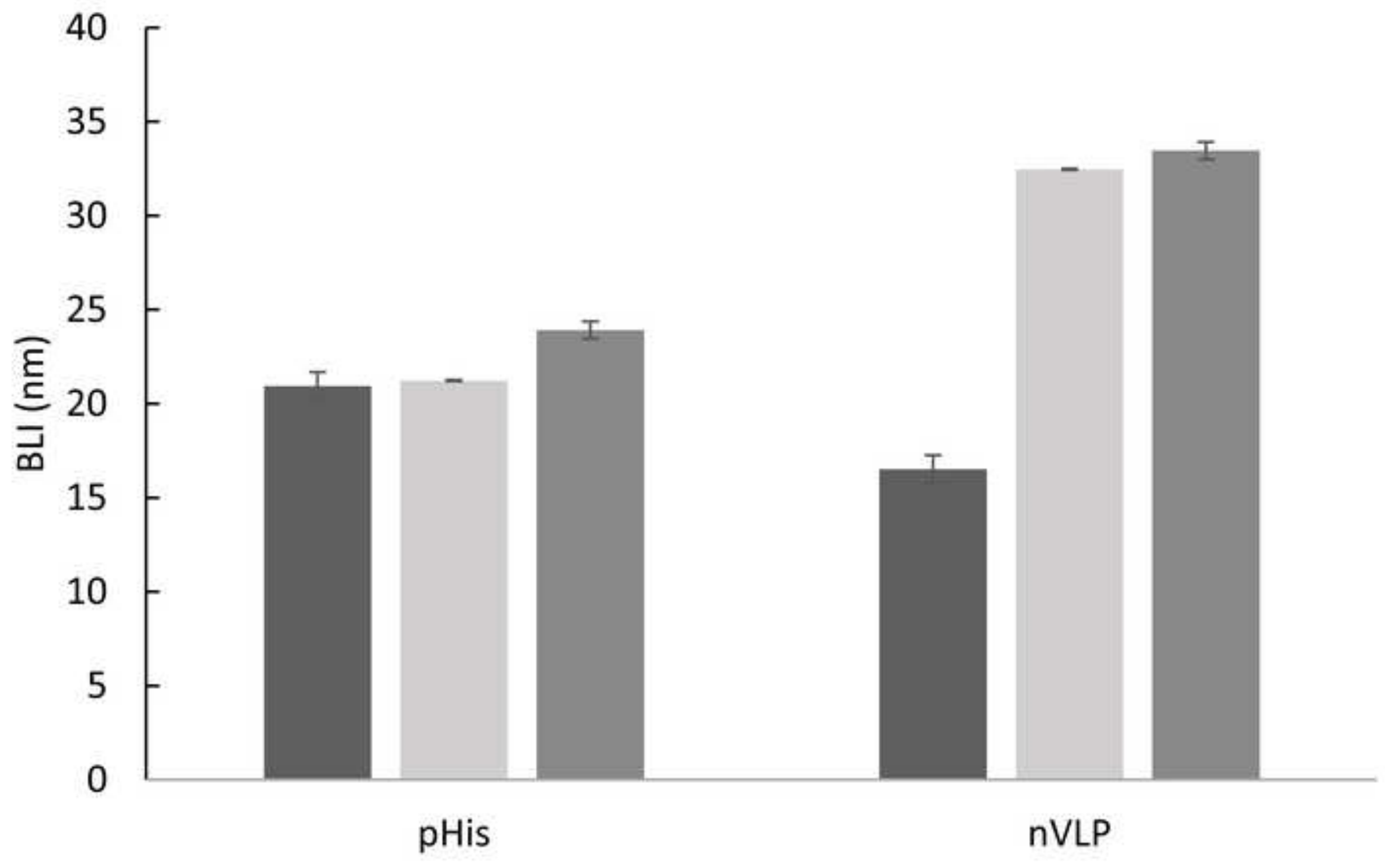

Ni: Non-oxidized Co: Non-oxidized $\quad$ Co: Oxidized 

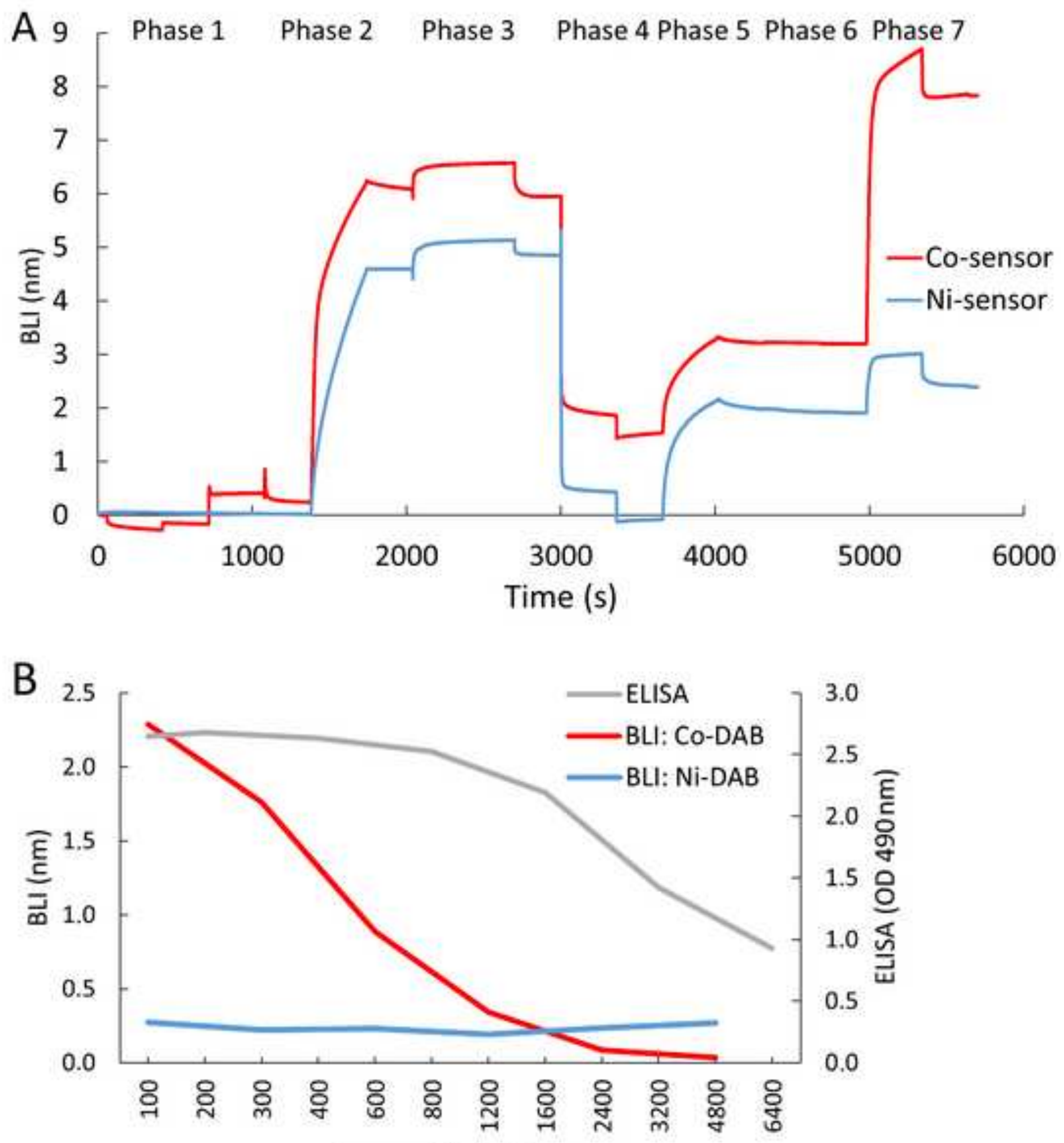

Serum dilution factor 